\title{
INVESTIGACIONES
}

\section{Feria intercultural y representaciones de lo migrante en una escuela urbana en Santiago de Chile*}

\author{
Intercultural Fair and the staging the migrant \\ in an urban school of Chile
}

\author{
Ramiro Catalán Pesce ${ }^{a}$ \\ ${ }^{a}$ Universidad de Concepción, Facultad de Ciencias Sociales. \\ ramirocatalan@udec.cl
}

\section{RESUMEN}

Este artículo se enfoca en el contexto educativo como un espacio privilegiado para analizar la construcción de procesos de inclusión-exclusión de estudiantes de familias migrantes que se insertan en el sistema educacional chileno. Se presentan resultados de una investigación etnográfica llevada a cabo en una escuela secundaria de la ciudad de Santiago de Chile donde se desarrolla un programa intercultural propio. El objetivo es analizar cómo una escuela al evaluar situaciones de potencial discriminación en sus aulas, primero categoriza las supuestas diferencias que hay entre sus alumnos, para posteriormente desarrollar ciertas estrategias de sensibilización sobre esas diferencias marcadas por la institución escolar. En este caso se analiza la puesta en escena de lo migrante y lo intercultural en una festividad específica de la escuela, la Feria intercultural, que conmemora cada año el 12 de octubre.

Palabras claves: educación intercultural, etnografía, migrantes.

\section{ABSTRACT}

This article focuses on the educational context as a privileged space to analyze the construction of inclusion/ exclusion processes of immigrant students in the Chilean educational system. This study presents the results of an ethnographic research carried out in a secondary school in Santiago, capital city of Chile, where its own intercultural program is developed. This research goes deeper into how a school evaluates circumstances of potential discrimination in its classrooms. Firstly, it categorizes the supposed existing differences among the students. Then, the school developed several awareness-raising strategies for its educational community based on these hypothetical differences. Specifically, this article analyzes the staging of immigrant and intercultural issues on a specific activity of the school, called "The Intercultural Fair", which commemorate every year the October 12th "Encounter of Two Worlds".

Key words: intercultural education, ethnography, migrants. 


\section{INTRODUCCIÓN}

Los movimientos migratorios son una constante de la historia de la humanidad, y en el caso de Chile lo anterior forma parte de la conformación de la nación como construcción social intencionadamente homogénea pese a que desde sus orígenes ha existido una diversidad de sujetos y comunidades al interior del territorio. Sin tener como objetivo plantear un estudio historiográfico (nada más lejos de los propósitos y alcances de este texto) sí es menester plantear una perspectiva diacrónica para tomar en consideración que aquello que hoy día se vislumbra en la opinión pública o desde sectores políticos como una "oleada migratoria" que irrumpe en "nuestra homogeneidad" no es un fenómeno exclusivo de esta época, aunque sí posee características particulares.

Las cifras demográficas muestran que, en Chile, actualmente hay 1.492 .522 migrantes internacionales (INE-DEM, 2020). Sin embargo, lo que si puede parecer más notorio es el crecimiento exponencial de la migración desde inicios del siglo XXI, impulsado en un primer momento, por personas de nacionalidad peruana que llegaron al país desde la década de los noventa (Stefoni, 2003; Tijoux, 2007; Garcés, 2011).

Este panorama ha encontrado su correlato en el sistema educativo chileno donde se ha hecho manifiesta la presencia de niñas, niños y jóvenes de otras nacionalidades en las escuelas, principalmente, municipales y particulares subvencionadas ${ }^{1}$. Según estimaciones, 167.780 estudiantes extranjeros se encuentran matriculados en estos tipos de establecimientos (Ministerio de Educación, 2020). Este último dato es relevante por cuánto permite apreciar que, aún enfrentados a una situación precaria vinculada a su status migratorio, una de las primeras instituciones con las que se conectan las familias migrantes, son las escuelas.

\section{LA TRIADA MIGRACIÓN, DIVERSIDAD Y ESCUELA}

Las particularidades del panorama migratorio actual en Chile, contrasta con otros procesos migratorios donde el país recibió durante buena parte del siglo XIX y XX, personas provenientes de la antigua Yugoeslavia (croatas y serbios, principalmente), de Alemania, de Italia, y de España. Aunque esos migrantes podían tener la necesidad de mejorar sus condiciones de vida o vinieran escapando de conflictos bélicos o sociales como los actuales migrantes, su condición de europeos les garantizó una posición social distinta a la que afrontan los migrantes que provienen de países de Sudamérica (Perú, Bolivia, Colombia, Argentina, Venezuela) o de Centroamérica (Haití y República Dominicana). Sin desmerecer, en absoluto, el esfuerzo y proceso de extrañamiento vivido por los migrantes sin distingo de origen ni época, surgen diferencias notorias entre una migración norte-sur (de Europa a Chile), y otra Sur-Sur (al interior de Latinoamérica). Diferencias que pueden vislumbrarse en prácticas de xenofobia, discriminación y racismo que afloran en distintas ciudades, barrios y escuelas de Chile, ante la presencia actual de extranjeros (Tijoux, 2013).

En el sistema educacional chileno, actualmente existen tres tipos de administración para las escuelas: municipal, particular subvencionada (administrada por privados pero subvencionada por el Estado) y particular pagada. Este panorama está siendo modificado paulatinamente por la implementación de los Servicios Locales de Educación. 
Esta situación plantea un primer desafío que es entender los procesos de inclusión/ exclusión de los migrantes bajo las claves de categorías de raza, cultura, nación, género, etnia, lenguaje, relaciones históricas, o jerarquización de nacionalidades en un relato que adquiere tintes neo-evolucionistas en la mirada de una parte de la sociedad de que Chile es un país más desarrollado que los otros países de Latinoamérica desde donde provienen los migrantes.

Estudios nacionales recientes sobre discriminación hacia los estudiantes extranjeros en los espacios escolares plantean un panorama de abierta tensión y menosprecio hacia los y las migrantes, donde aparece la categoría de raza como un marcador de discriminación hacia niñas, niños y jóvenes (Stefoni et al., 2008; Pavez, 2012; Tijoux, 2013; Jiménez, 2014; Jiménez y Fardella, 2015; Riedemann y Stefoni, 2015; Bustos y Gairín, 2017).

Pero, en modo alguno, es sólo la referencia racial (vinculado a un fenotipo, el color de piel más oscuro) el único marcador de discriminación que aparece. Por el contrario, surge en otros espacios escolares una discriminación aditiva (Crenshaw, 2002), donde se van sumando y agregando otras diferenciaciones negativas. Por ejemplo, con la etnia o la nación, en escuelas del norte del país, en aquellas regiones ${ }^{2}$ que tienen una historia de relaciones conflictivas marcadas por la "Guerra del Pacífico", donde se ha desarrollado una mirada despectiva, y de superioridad hacia las personas que provienen de Perú y Bolivia. Cuya posición desventajosa en esa latente jerarquización de naciones que aflora en el imaginario nacionalista chileno, suele cruzarse también con referencias negativas sobre la condición, supuestamente visible en sus rostros y pieles, de su indianidad (Rivera Cusicanqui, 2010).

La noción de Crenshaw (2002) sobre la interseccionalidad, plantea los múltiples cruces del género con otras categorías sociales que particularizan y complejizan la mera mención a la discriminación de género como algo homogéneo y continuo. Lo que permite apreciar que la discriminación que pueden enfrentar los y las migrantes, en términos concretos opera de manera múltiple. Son discriminaciones que se superponen, reafirman y parecen naturalizarse, aun cuando son históricas y obedecen a contextos culturales particulares (Viveros, 2016).

Esa sumatoria de potenciales discriminaciones que deben confrontar las personas de otras nacionalidades que viven en Chile es visible en las escuelas y liceos del país. Donde los espacios educativos son ahora compartidos por nacionales y extranjeros. Lo que, de algún modo, le da al contexto escolar una imagen de sitio privilegiado para pesquisar las dinámicas de inclusión y exclusión en que se ven envueltos las y los participantes de la comunidad escolar.

En este sentido, la escuela como dispositivo de producción y reproducción cultural ocupa un lugar central en las reflexiones e investigaciones desde las ciencias sociales en general (Bourdieu y Passeron, 1996; Lahire, 2004; Willis, 2006), y desde la antropología en particular. Tomando como punto de partida el interés manifiesto de esta disciplina desde sus exponentes más clásicos (Benedict, 1971; Mead, 1985; Boas, 2008³) por los procesos de reproducción cultural que se vinculaban con modalidades de educación formales y no formales en una diversidad de sociedades. La escuela de cuño occidental, tributaria de la modernidad y de alcance público se erige progresivamente en un objeto de estudio

Referidas a la Región de Arica y Parinacota, Región de Iquique y Tarapacá, y Región de Antofagasta.

Por mencionar sólo a algunas y algunos representantes fundacionales de la disciplina. 
primordial para comprender la formación de ciudadanos en el marco de los estados-nación contemporáneos.

En el caso de Chile, distintas investigaciones han evidenciado la presencia de diferentes posibilidades de gestión de la diversidad cultural en contextos educativos, tanto relativo a los pueblos originarios (Chiodi y Bahamondes, 2001; Bolados, 2006; Catalán, 2013) como también vinculado a la presencia de alumnado migrante (Stefoni et al., 2008; Jiménez, 2014; Jiménez y Fardella, 2015; Tijoux, 2016; Bustos y Gairín, 2017). Desde aquellas políticas de gestión de la diversidad que plantean una lógica asimilacionista con respecto a la sociedad de acogida, como las que fomentan una pedagogía de corte intercultural vinculada a las corrientes multiculturalistas.

\section{ASPECTOS METODOLÓGICOS}

Los resultados presentados en este artículo surgen de la investigación doctoral llevada a cabo mediante trabajo de campo etnográfico realizado durante tres años en una escuela secundaria ubicada en una comuna de la zona norte de Santiago. Este estudio etnográfico, se desarrolló mediante una aproximación complementaria entre la observación participante y la no participante, entendidas como estrategias dinámicas de producción de datos que se adaptan de manera flexible a la cotidianeidad del contacto intersubjetivo entre comunidad e investigador (Guber, 2005). También se realizaron entrevistas etnográficas (Flick, 2007) de carácter semi-estructuradas y en profundidad a docentes, educadores tradicionales ${ }^{4}$, directivos, así como también entrevistas grupales y conversaciones cotidianas con estudiantes chilenos y extranjeros.

La decisión de realizar etnografía en dicha comunidad escolar permitió no sólo describir las prácticas sociales y discursos asociadas al proceso de categorización de lo migrante y a la puesta en escena de la Feria Intercultural, sino que también permitió profundizar narrativamente en una interpretación contextual (Geertz, 1989) que develara las contradicciones, tensiones y negociaciones que surgen en el espacio escolar.

\section{RESULTADOS}

\subsection{CATEGORIZANDO LO MIGRANTE EN LA ESCUELA}

En esta escuela secundaria ${ }^{5}$ ubicada en la ciudad de Santiago, la presencia de los estudiantes de familias inmigrantes tenía la particularidad de situarse en un establecimiento educacional que desarrollaba un proyecto intercultural propio pero orientado en un principio a los estudiantes que pertenecían al pueblo mapuche. Lo distintivo de este proceso vinculado a la llegada paulatina de estudiantes de otras nacionalidades a un Liceo que ya tenía

\footnotetext{
$4 \quad$ Personas de las comunidades y asociaciones indígenas que se incorporan a la escuela para enseñar aspectos de sus culturas. En la gran mayoría de las escuelas conforman una dupla pedagógica con un docente titulado. Sin embargo, en esta escuela una de sus particularidades era que detentaban la figura de "talleristas", es decir en el papel sólo realizaban "talleres", lo que les permitía desarrollar las actividades de enseñanza de manera autónoma sin la presencia de un/a docente.

200 estudiantes aproximadamente, con edades entre 14 y 18 años, distribuidos en cursos de primero medio a cuarto medio.
} 
en marcha un proceso de valoración de la diferencia cultural, según lo expresado en su proyecto educativo interno, permitió apreciar ciertas dinámicas interesantes en torno al ajuste, negociación y generación de una supuesta "convivencia intercultural”.

El discurso de valoración de la diversidad que promueve el proyecto intercultural se elabora para evitar el racismo y la discriminación, vale decir la diferenciación negativa, estereotipada y violenta hacia los alumnos "percibidos" como indígenas o migrantes, por parte del resto de los y las estudiantes, como lo señalaban continuamente los y las docentes y directivos de la escuela.

Uno de los primeros atisbos sobre el modo en que se despliega la gestión de la diversidad en esta escuela se advierte en que el liceo no escapa a la lógica de categorizar a los estudiantes. Identificando a aquellos que pueden ser objetos de discriminación, y para ello, los diferencia de los demás, contribuyendo a dotarlos de una imagen también estereotipada. Si en el caso de los estudiantes de apellido indígena, se plantea la referencia a que "son los alumnos mapuches", luego con la aparición de los estudiantes extranjeros surge un nuevo rotulo: "son los alumnos migrantes".

En el caso de los jóvenes que provienen del extranjero, su categorización deviene desde el momento en que presentan sus papeles para ingresar al Liceo (certificados de nacimiento, por ejemplo), y en algunos casos también del hecho de que los venga a matricular la encargada de la Oficina de Migrantes de la comuna ${ }^{6}$.

El contacto entre estudiantes de distintas nacionalidades al interior del Liceo era un hecho cotidiano pues en la misma aula podían encontrarse adolescentes chilenos, colombianos, ecuatorianos, palestinos y haitianos sin que yo hubiera observado, al menos durante el periodo de trabajo de campo de tres años ${ }^{7}$, situaciones de discriminación y/o violencia física y sicológica tanto evidente como implícita. Lógicamente esta referencia hay que tomarla con cuidado porque eso no quiere decir que no se produjeran otros tipos de prejuicios o conflictos quizás más soterrados o sutiles, fuera del campo visual de la mirada etnográfica. De hecho, sólo un par de conflictos entre estudiantes llegaron a mis oídos y uno de esos fue el de las estudiantes haitianas que ya se habían ido del colegio cuando yo comencé mi investigación.

A juicio de los profesores nunca hubo conflictos con ellas, sin embargo, un par de estudiantes chilenas me comentaron que sí existieron altercados con las jóvenes haitianas porque

Eran pesadas ${ }^{8}$, no se juntaban con nadie, y de repente se enojaban y te gritaban que te iban a acusar por discriminación... y no les habíamos hecho nada (estudiante chilena).

En ese sentido, llamaba la atención que en el día a día de este liceo se apreciaba bastante tranquilidad, lo que contrastaba con la imagen recurrente percibida en una parte de la sociedad chilena, de que un establecimiento municipal secundario en una comuna de bajos ingresos económicos es sinónimo de un ambiente violento, tenso y conflictivo

6 La comuna donde está emplazado el Liceo se ubica en la zona norte de la ciudad de Santiago y representa una de las comunas con más población extranjera de Chile, cercana al 8 \% (IND, 2017).

$7 \quad$ Basado en observación participante y no participante, conversaciones y entrevistas semi-estructuradas, y en profundidad realizadas a distintos actores de la comunidad escolar.

$8 \quad$ Por "pesadas" se refieren a una persona que es demasiado "seria", llegando a ser "antipática". 
(Canales, Bellei y Orellana, 2016). También los discursos de profesores, estudiantes y apoderados iban en dicha dirección, destacar su "no violencia" como un valor en sí mismo.

Quizás esa particularidad de ser un liceo con mejor convivencia escolar, alentado en gran parte por su proyecto intercultural, hace que se remarque aún más esa cierta animosidad entre las jóvenes haitianas y los estudiantes chilenos. De hecho, es interesante que incluso esa tensión en sus relaciones sociales sea comentada también por estudiantes que se reconocen como mapuche.

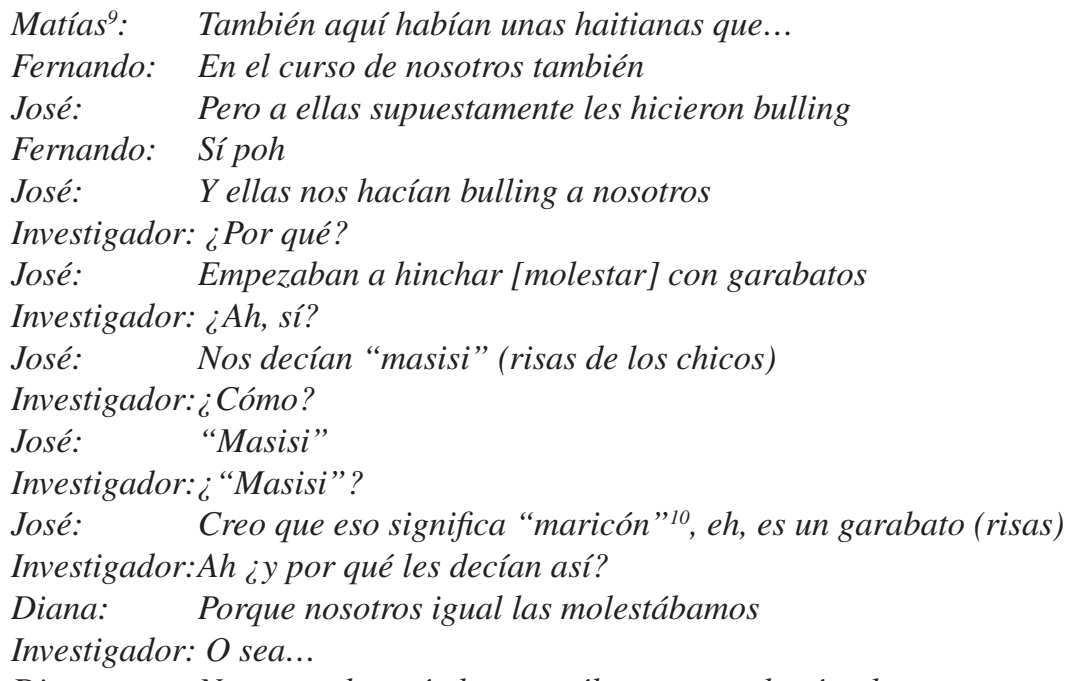

Diana: $\quad$ Nosotros después las acusábamos y se hacían las tontas, que ellas no eran, que éramos nosotros... (estudiantes chilenos).

A pesar de que estos conflictos, a los que aluden los estudiantes, no pude observarlos, sí pude complementarlos con la información de que estas alumnas haitianas al cabo de unos meses se retiraron del liceo. La encargada de la Oficina de Migrantes de la Municipalidad me señaló, sin dar más detalles, que esto se debió a problemas de integración y a que el Liceo no tuvo la capacidad de poder motivarlas para que se mantuvieran ahí.

Tanto el problema de comunicación, que algunas docentes señalaron como causa de los conflictos, vinculado a que las estudiantes haitianas sólo hablaban creolé (aunque se puede hipotetizar que algo de castellano debieron haber aprendido para poder tener discusiones con sus compañeras chilenas), como el de una importante sumatoria de marcas de otredad con las que eran representadas por la comunidad escolar, constituyeron una complejidad inasible para la institución escolar y sus herramientas de trabajo intercultural: "Ni siquiera eran latinoamericanas, las pobres. Su cultura era caribeña" (Profesora F.).

Estas marcas de diferencia se entrelazaban formando una múltiple representación sobre su carácter de otredad. Pues tanto profesores como estudiantes, aun cuidando el uso de sus palabras para evitar decir algo "políticamente incorrecto", señalaban como parte de las características de las jóvenes haitianas su fenotipo de piel oscura (diferencia racial), su

\footnotetext{
Los nombres de estudiantes y docentes han sido cambiados para mantener su anonimato.

10 Calificativo despectivo para referirse a una persona homosexual.
} 
idioma creolé (diferencia lingüística), su procedencia haitiana (diferencia nacional), y su personalidad percibida como "fuerte" (diferencias conductuales de género). De este modo, la representación construida en torno a ellas se basaba en un agregado de diferencias que las constituían a ojos de la comunidad escolar como una otredad "compleja" incluso para un liceo que trataba de construir un imaginario intercultural. La discriminación aditiva (Crenshaw, 2002) en este caso se mostraba como un factor de exclusión en el espacio educativo.

Más allá del caso puntual de estas alumnas, parece interesante detenerse sobre cómo el proyecto intercultural del liceo orientado desde sus inicios a esa otredad étnica, referida a los pueblos indígenas, amplía su foco sobre una "otredad" extranjera que comienza a ser percibida al interior de la escuela. En ese sentido, esas dos otredades serán categorizadas de manera distinta por los agentes de la institución escolar. Lo indígena se relacionará con lo "propio", no en vano también se les denomina "culturas originarias", mientras lo migrante se leerá como lo "ajeno". Un contraste que juega con las nociones de lo interno y lo externo que ha procesado el Estado con su proyecto de nación, y del cual es tributario la escuela.

Por contrapartida a esta problemática inclusión, más bien exclusión, de las jóvenes haitianas, se destaca el caso de dos hermanos palestinos que llegaron al liceo y que sí eran objeto de orgullo para la comunidad escolar por las buenas relaciones que mantenían con sus compañeras y compañeros chilenos. Estos jóvenes llegaron al liceo también de la mano de la encargada de la Oficina de Migrantes de la Municipalidad, pues estaban en calidad de refugiados en el país. Venían con sus padres y traían una historia familiar marcada por las guerras en medio oriente, lo que era de conocimiento para sus compañeros.

José: $\quad$ Yo tengo un compañero que es palestino y creo que le costó; porque allá escribían pa' al revés (simula escribir en el sentido de derecha a izquierda), y pa' acá y también es así para, y aquí es pa'l. Y creo que le costó, y ahora dice que se le está olvidando más o menos el idioma de él.

Carlos: $\quad$ Sí po'si cuando no practicai'se te olvida.

Tomás: $\quad$ No, pero cuando lo llaman por teléfono, cuando lo habla con su propia voz, sí habla con su idioma.

José: $\quad$ Allá en la casa de él hablan el idioma, porque allí se entienden.

Investigador: ¿Y les cuenta algo de su país?

José: $\quad$ No mucho, porque allá pasaban en guerra. De su país, no tengo ganas de preguntarle.

Matías: De hecho, yo una vez me senté a conversar, no con, o sea no que, no sentar a conversar con él; sino que nos sentamos a estudiar en la biblioteca. Y tuvo un pasado bien difícil él allá, se le murieron hartos, en bombardeos y todo eso en guerra, se le murieron hartos familiares. Así que igual vi que, cuando supe de eso dejé de, onda, de agárralo pa'l... Lo hueviabamos [molestábamos] mucho.

José: $\quad$ De repente me dice a mí, que extraña a los abuelos y a los tíos; quiere, quiere ir pa'allá, pero de visita nomás (estudiantes chilenos).

Lo señalado por estos estudiantes es significativo pues asumen que en cierto sentido el conocer las dificultades y penurias que debió afrontar su compañero palestino los hizo empatizar con él y dejaron de molestarlo. 
En el trabajo de campo pude observar que los jóvenes palestinos se relacionaban con sus compañeros y profesores, casi siempre sonriendo y se mostraban amistosos en su trato, pero evitaban hablar de su vida en Palestina. Luego supe que también habían vivido en Irak: "Vine a Chile hace cuatro años soy de Irak; pero mi origen es palestino, no soy de Irak y estoy en el Liceo..." (estudiante palestino).

En todo caso, como se apreció en el caso de las estudiantes haitianas, no todas las historias de los alumnos migrantes se desarrollaban a través de una ruta de aparente inclusión. Un relato distinto es el que nos aportaba una profesora sobre un alumno palestino que había llegado hace unos años al Liceo y que se retiró después de unos meses porque lo molestaban por su apellido: Khalifa. Una palabra que en Chile se usa popularmente como apodo para señalar a una persona que es libidinosa. Ante esto, esa profesora se encogía de hombros para después señalar: "era imposible que no lo molestaran".

Pese a estas situaciones más conflictivas, los procesos de diferenciación con los alumnos migrantes, según algunos profesores, serían menos conflictivos pues suponen que dichos jóvenes ya tendrían su identidad construida y por tanto reivindicarían su diferencia sin problemas. Probablemente el representar a los alumnos extranjeros como exentos de la necesidad de ser "inculcados" en una identidad, remita a la mirada del Estado que permea en algunos momentos el discurso pedagógico, poniendo el foco de su interés en la propia nación y simplificando a lo externo a través de esencializaciones que reducen su condición de complejidad.

\begin{abstract}
Además, el inmigrante que llega, llega con un tema de identidad resuelto, lo trae y es lo que lo fortalece en el espacio. Ellos llegan a Chile formándose, comunicándose con los que son de su país, siguen teniendo su comida, siguen escuchando su música, siguen con su timbre, no sé si es su timbre, pero es su fonética, su habla. El tema está en nosotros, en la identidad del mapuche, del... no, el inmigrante no lo tiene, al contrario, se hace valer y le gusta sentir esa diferencia. El colombiano no cambia su timbre, su forma de hablar, el argentino tampoco y el ecuatoriano tampoco, y ellos se imponen y se reconocen (profesora M.).
\end{abstract}

A través de estos discursos se aprecia la elaboración que se hace en torno a la idea de que no siempre marcar una diferencia implica una exclusión o una discriminación. En palabras de distintos docentes, que aquí ejemplifica M., esto se refiere a que en el trato cotidiano muchas veces los alumnos se nombran por su nacionalidad, no estando, supuestamente, presente un tema de prejuicio, sino que de diferenciación.

El chileno siempre le va a decir y se van a mencionar como, en un principio yo escuche y me llamo la atención, "ah, pero mira el argentino". Pero no es por menoscabar sino es por una forma de identificarlo. Entonces, "mire el argentino pos' profe". "No, es el Johan”, entonces yo le pregunto ¿pero, cómo se llama él? “Johan”. ¿Y por qué le dices el argentino? "Porque es el argentino po', el único del curso". Pero no es por menoscabarlo (profesora M.). 


\subsection{DISPOSITIVOS DE VALORACIÓN DE LA DIFERENCIA: LA FERIA INTERCULTURAL DEL 12 DE OCTUBRE}

Una de las celebraciones de mayor importancia para el Liceo, es el de la Feria Intercultural, que se realiza en octubre como un modo de conmemorar la llegada de Colón al continente. Esta Feria se organiza en torno a una serie de $\operatorname{stands^{11}}$, o tiendas, dedicadas a representar un mиestrario de cada cultura identificada por la institución escolar en su espacio. A través de la identificación del alumnado con categorías nacionales (Ecuador, Colombia, Perú, Haití, Palestina), o con categorías étnicas (culturas madres, cultura mapuche, cultura aymara, cultura rapanui). Significativo es que no hay ningún stand de Chile, como si el implícito fuera que es la otredad la que se da cita en esta feria, y que lo que constituye lo dominante desde la lógica escolar, lo chileno, fuese invisibilizado por unas horas, al menos simbólicamente.

Cada stand está organizado para mostrar elementos supuestamente característicos de estos pueblos originarios y también de esas naciones. Artesanías, información sobre sus tradiciones, alimentos, forman parte de una selección realizada por los profesores, educadores tradicionales, estudiantes y familiares que forman parte de las comisiones de gestión de cada stand. Con el objetivo declarado, que aparece tanto en el proyecto de la escuela como en las entrevistas a sus directivos, de buscar visibilizar la presencia de las distintas culturas que convergen al interior del liceo.

Durante el segundo semestre de cada año, en cada curso, profesores, educadores tradicionales y estudiantes, destinan una parte importante de lo que se trabaja en las asignaturas de culturas originarias a preparar lo que será expuesto en cada tienda para su expresión visual y espacial en el patio del liceo.

El patio parece tomado por una serie de tiendas de color blanco, cada una con un letrero para que no quepan dudas de a cuál cultura pertenece la expresión de cada stand. Pese a la preeminencia del color blanco, también se advierte lo multicolor de banderas, pañuelos, y vestimentas típicas que algunos alumnos, hombres y mujeres, llevan como parte de su puesta en escena. Pienso rápidamente si ese contraste entre tiendas de color blanco y el colorido presente en lo expuesto, funcionará en algún nivel como una metáfora de lo homogéneo de la institución escolar versus la diversidad de los grupos sociales. O probablemente sólo sea una coincidencia, quizás las telas blancas que forman paredes y techo de las tiendas eran simplemente las más baratas (Notas de campo, octubre 2010).

Algo que llama la atención de esta Feria Intercultural, es que si bien, fue planteada como una actividad de "puertas abiertas" para la comunidad del barrio circundante, y en especial para las familias de los estudiantes, la participación de padres y madres es más bien escasa. En todo caso, un hecho indesmentible es que al realizar esta convocatoria en día semanal y en horario laboral, se reduce a su mínima expresión la posibilidad de que éstos asistan.

$Y$ ahora en las proximidades del 12 de octubre se realiza ahí una feria de la interculturalidad, un poco dar a conocer estas cosas y todo a la comunidad. Y sale por la comunidad entre comillas, porque la verdad somos nosotros (director).

11 Esa es la denominación que le confiere la comunidad educativa de esta escuela. 
De todos modos, en los stands de países, se puede observar la presencia de las madres que han preparado algún alimento característico de sus naciones, y que también asisten para acompañar a sus hijos.

Una característica que resalta de la feria es que en varios stands sólo se observan estudiantes a cargo. Sus funciones se abocan a explicar qué es lo que destacan de particular de su país, por ejemplo, mostrar los elementos que exhiben como propios de su nación, objetos de artesanía, la bandera, el respectivo baile nacional, o bien, presentar alguna comida típica para degustar.

En ese sentido, hay un enfoque folclorizante que se deja ver de forma casi transparente en esta puesta en escena de la institución escolar pretendidamente intercultural. Donde las sociedades de origen de los estudiantes migrantes se caracterizarán con acuerdo a una selección de símbolos de cierta materialidad vinculados a una tradición que supuestamente deviene en identidad para aquellos países. No es baladí el hecho de que sean los mismos estudiantes extranjeros (y algunos de sus familiares) los que sigan este juego que ofrece la escuela, y presenten una visión modélica de sus sociedades. Pues son ellos, la mayoría de las veces, quiénes seleccionen estos elementos para representar las características de sus países.

\begin{abstract}
Para la feria, era, es mi fiesta ¿me entiende? No tenía eso de ritual, pero tampoco tenía la cosa del acto artístico, si no que estamos en fiesta, en fiesta intercultural, era como otra sensación, ¿ya? Entonces antes era muy así... incluso un año ningún niño quiso bailar y los profesores bailaron, hicieron un pequeño baile, los profesores, porque los chiquillos no quisieron, pero era eso más o menos como presentar algo del colegio, pero en cierta manera era un disfraz y la idea es que el que baile lo sienta porque tiene su espiritualidad (profesora C.).
\end{abstract}

Dotar a los símbolos y significantes que se enarbolan en esta conmemoración de la diversidad, también conlleva un desafío mayor. Sobre todo, para las coordinadoras del área intercultural de la escuela, como en el caso de la profesora C., principal artífice de este proyecto intercultural, que plantea la necesidad de que la expresión visual, artística también posea "espiritualidad", contenido, sentimiento. De otro modo queda en el aire el riesgo de que la festividad torne en mero "disfraz", en performance sin sentido.

Pude observar en dos oportunidades la feria intercultural, en 2010 y en $2012^{12}$. En dicho año, las tiendas dejaron atrás el color blanco, y se hizo predominante el azul. Los stands alusivos a los estudiantes migrantes eran los de Colombia, Ecuador, Palestina y Perú ${ }^{13}$. Como ya señalé, en cada uno de estos puestos se encontraban como anfitriones a un par de estudiantes de dichas nacionalidades.

12 En 2011, la Feria no se realizó debido a una "toma" del liceo realizada por sus estudiantes. Esta medida de presión estudiantil, que se caracteriza por la ocupación y el control de los espacios de la escuela, se enmarcó en las movilizaciones de estudiantes secundarios que abarcaron todo Chile en demanda de una reforma a la educación que garantizara condiciones de gratuidad, calidad y equidad en el sistema educativo. Dicha toma se extendió por varios meses, lo que "impidió prepararla [feria]en forma adecuada" en palabras de una profesora.

13 También estaban presentes los Stands de Cultura Mapuche, Cultura Aymara, Cultura Rapanui y Culturas Madres. Debido a la temática específica de este artículo y a lo acotado de la extensión, éstos no serán desarrollados acá. 


\subsubsection{Representaciones de denuncia: El stand de Palestina}

Pese a que el contexto en el que se despliega esta actividad es el de las culturas latinoamericanas enfrentadas a la conmemoración del 12 de octubre como hito que cambió drásticamente la existencia de todos los pueblos del continente, la presencia de un par de estudiantes palestinos implicó que se incluyera su participación como un modo de mostrar ese sentido intercultural que en el imaginario del liceo excede lo regional y continental. En ese sentido, el stand es producido por dichos estudiantes en un tono de denuncia, con un carácter político fuertemente marcado por sus trayectorias vitales que refieren a conflictos bélicos, diásporas y su status de refugiados.

La narración fragmentaria que se elabora desde esas experiencias se plasma en este stand desde un inicio con la posición central que ocupa un cartel donde se representa la bandera de Palestina. A un costado aparecía un afiche donde estaba escrito "Palestina" en idioma árabe. También se leía en un volante, "Palestina libre", acompañado de la foto de un niño con un pañuelo árabe cubriéndole el pelo y parte del rostro. A su lado se podía observar el "Escudo de Palestina" que mostraba un águila posada sobre un emblema patrio. En la parte inferior de dicho cartel aparecían dos imágenes de fotos de soldados israelíes deteniendo a manifestantes palestinos.

En otro cartel titulado "Palestina", se ve una imagen de un niño palestino lanzando piedras a un tanque de Israel, sobre la imagen en blanco y negro está escrito en color verde con un lápiz destacador: "Pueblo oprimido".

Al lado de esta imagen hay un cuadro de texto que se titula: "La actualidad de Palestina" que entrega datos sobre "capital" y "población" que señala: "7.000.000, de ellos 4.000.000 de refugiados que viven en el exilio a raíz de la ocupación israelí de sus tierras". También aparece información sobre "el ambiente", "el pueblo", "religión", "idioma", "Partidos políticos" con el texto más extenso del cuadro, para explicar la situación política de Palestina.

En el costado inferior derecho, otra imagen muestra a una mujer árabe en la explanada de las mezquitas frente a la Cúpula de la Roca en Jerusalén, sobre esa imagen escrita a mano con un lápiz de color naranjo se lee: "Pueblo muy religioso".

Una fotografía (también fotocopiada en blanco y negro) que llama la atención es la del futbolista Kanouté, originario de Malí, que tras un partido con su club Sevilla mostró que debajo de la camiseta de su equipo llevaba otra con la leyenda: "Palestina". En la imagen aparece abrazando a otro futbolista, Luis Fabiano. Sobre la imagen, otra vez escrito a mano se lee: "El deporte los une".

Es interesante el carácter político asociado al stand de Palestina, desarrollado por los alumnos palestinos en cooperación con otros estudiantes del liceo. Las imágenes y referencias escritas tienen un tono de denuncia y lejos de haber sido censurados, están presentes a la vista de todos. Incluso es sugerente el hecho de que, al estar al lado del stand mapuche, la bandera palestina y la bandera mapuche casi se rocen... Como dos símbolos de resistencia cultural y política.

En otro ámbito, se mostraban también productos gastronómicos como un repertorio característico de Palestina, alimentos y dulces para degustar. Los cuáles contaban con una breve presentación en el mismo cartel ya descrito.

De este modo, se expresaba una selección de símbolos e imágenes que tratan de representar, sintetizar, resumir e incluso condensar la complejidad de toda una nación en 
diversos niveles: políticos, sociales, religiosos y gastronómicos. En el espacio reducido del stand se elabora fragmentariamente un collage que remite a un pueblo, y que plantea una crítica a la situación de dominación a la cual está enfrentado.

\subsubsection{Representaciones del Estado Nación: Los stands de Ecuador, Perú y Colombia}

En el caso de las tiendas que buscan caracterizar a estos tres países existen paralelos significativos entre ellos. Se enarbolan recurrentemente los símbolos patrios (bandera, escudo, colores nacionales), artesanías y vestimentas folcklóricas, y productos gastronómicos como ámbitos que representan a esas naciones. Emerge con claridad un repertorio de imágenes que la construcción del Estado Nación suele tomar como referencia, siguiendo a Anderson (2007), y que posibilita la construcción de una comunidad imaginada que se ve representada en ciertos emblemas.

En el stand de Ecuador, aparecía el tricolor (amarillo, azul y rojo) característico de su bandera afirmada a un costado de la mesa donde se desplegaban diversos objetos artesanales y preparaciones gastronómicas.

En un mapa de América del Sur que diferenciaba por colores los distintos países, la zona correspondiente a Ecuador mostraba a su lado tres carteles hechos a mano con información demográfica del país, sus principales ciudades y su geografía.

Sentada en una silla tras la mesa, se ubicaba una alumna ecuatoriana sonriente y presta a responder cualquier duda o comentario sobre el panel que trata de ser informativo de su país. En éste se destaca la diversidad ecológica del país, sus áreas geográficas de selva, sierra y costa. También hay menciones a su gastronomía, y a sus productos de exportación más característicos: café, plátano y cacao.

Yo pienso que, si nos hubiésemos organizado mejor, hubiese salido imás bonito!, salió bonito, pero hubiese salido más bonito; porque, por ejemplo, el profe me había avisado que quería hacer una comida, ipero por esos días justo a mi sobrinito se le antojó nacer!, así como de la nada, entonces era como que en mi casa no había nadie, le dije "no profe no puedo" (estudiante ecuatoriana).

Uno de los alimentos que se ofrecían era plátano frito que aparecía dispuesto en trozos pequeños sobre un plato blanco, y del cuál las personas que pasaban iban sacando para degustar. En una referencia más de que el aspecto gastronómico, se presenta como una seña de identidad nacional ineludible para los estudiantes extranjeros, y a la vez como una carta de presentación, un símbolo valorable, por sus pares chilenos y por las personas que van deambulando por la feria.

La estudiante a cargo del stand estaba vestida con un traje típico de su país, un vestido largo y colorido, de modo que, ataviada así, la joven también se simbolizaba como representante de su país. Su puesta en escena y simpatía fue motivo de variadas felicitaciones tanto por sus compañeros de curso como por las y los profesores: "Yo parecía famosa, a cada rato me pedían fotos y era como "aah, aah" (estudiante ecuatoriana).

En el caso del stand de Perú, también se mostraba de manera icónica al emblema patrio (rojo, blanco, rojo). Colgado del techo de la tienda aparecía un sombrero azul con un par de listones azul y rojo que lo envolvían. A cargo del puesto, se encontraban un par de alumnos 
que conversaban y ofrecían para degustar unas porciones pequeñas de ceviche ${ }^{14}$, de $\operatorname{chuñ} o^{15}$ y maíz. También se observaban unos platos ya vacíos debido al éxito que habían tenido con los comensales. Una breve descripción en papel señalaba lo que había sido su contenido: Papas a la huancaína ${ }^{16}$, y mazamorra morada ${ }^{17}$.

De este modo, esa referencialidad a la bandera, al folklore y a la gastronomía como elementos caracterizadores de su nación, se repite no sólo en el stand de Perú sino también en el de los otros países. Es una exhibición de elementos, productos y símbolos que se ofrecen al observador de manera inconexa, dispuestos sobre un mantel, con alguna mención que los identifique, pero no necesariamente que los explique, ni que demuestre su importancia para esa comunidad.

Quizás esa falta de un contexto explicativo se pueda entender en la idea de que para los organizadores de esos stands (alumnos y profesores) ese supuesto patrimonio no exige más explicación, pues se entendería obviamente su vínculo relevante con ese país. Así esos elementos serían percibidos como "naturalmente" característicos.

En la tienda de Colombia, una estudiante de esa nacionalidad cubría parte de su uniforme escolar con un poncho ${ }^{18}$ con los colores de su bandera (amarillo, azul y rojo), en otra referencia vivida sobre la identidad nacional como expresión de símbolos patrios personificada en una joven. A un costado del stand, también se observaba un cartel donde eran destacados algunos datos de población del país.

Otro estudiante colombiano llevaba puesto sobre su uniforme escolar, la camiseta de la selección de fútbol de Colombia. Este joven muy sonriente avisaba a viva voz "café colombiano para todos", para luego servirlo en unos pequeños vasos ante la solicitud de otros estudiantes que pasaban frente a esta tienda. En otro lugar destacado del stand, se ofrecían arepas dispuestas en platos sobre la mesa.

La idea de las "comidas típicas" aflora como un ejercicio de exhibición de aquello que, por una parte, es presentado como un fragmento del patrimonio cultural de esos países, y por otra parte, ofrece simbólicamente a quién degusta esos productos, algo del aroma y del sabor que recuerdan y representan de la patria lejana, con una dosis relevante de nostalgia y añoranza.

Y uno no las puede tener (las comidas tradicionales), en mi caso especial, arepas no, no puedo hacer arepas como hacía allá porque no tengo la harina, cosas así (estudiante colombiano).

\footnotetext{
Plato característico de la cocina peruana, en base a trozos de pescado marinados en jugo de limón y variadas especias. 


\section{DISCUSIÓN}

La feria intercultural se concibe como parte de las actividades de sensibilización y visibilización que son trazadas de manera explícita en el proyecto intercultural de esta escuela y que obedecen a una lógica de fomentar un ambiente de tolerancia y de respeto por las diferencias ya sean categorizadas por la institución escolar como étnicas o migrantes. Esa institucionalización de lo intercultural va a funcionar, cómo no, en clave escolarizante, vale decir, segmentando la vida social en parcelas específicas que son procesadas de manera abstracta (Dietz, 2003; Franzé, 2005).

Ese sentido normativo con que se operacionalizan estas actividades viene a reflejar la sedimentación en las prácticas sociales, focalizadas en un tiempo y lugar específicos pero transversalizadas a toda la comunidad, de esta suerte de rituales que reflejan las representaciones supuestamente vinculantes que han sido expresadas por la institución escolar en un tono declarativo (Díaz de Rada, 1996), como mero discurso.

\section{Porque también discrepo en eso, si yo hago una cultura folclorizante (me) alejo del concepto, porque ellos (las y los estudiantes) simplemente van a hacer folklor y no van a saber y no les va a servir para la vida. Y lo que esto pretende es (ser) un agente de cambio y yo quiero que reflexionen en esa dinámica, que construyan la realidad (profesora M.).}

Lo migrante se focaliza en estas expresiones y actividades comunes en el ámbito escolar, como una puesta en escena que pretende entregar una representación, que deviene fragmentaria e incoherente, de una sociedad. En dicho sentido, seleccionar, presentar y exponer elementos supuestamente característicos de los países de donde provienen los estudiantes migrantes como si fuese una "enumeración caótica" (casi en términos poéticos) es una alegoría muy consistente con el modo en que gestiona la diversidad una entidad tan homogenizante como la escuela.

Ahora bien, pese a ello, en la comunidad escolar también surgen voces que aluden a esa necesidad de plasmar la diversidad cultural, sin el imperativo de organizarlo, darle un orden establecido, ni segmentado. Ahí aparece otro modo de representar lo intercultural y que es en clave de collage que se visibilizan parcialmente culturas, naciones, tradiciones y globalización.

Claro, entonces ahí, "chuta, ¿cómo metemos el hip hop, la Shakira y el canto en inglés? Con el inglés me refiero a..., haciendo un discurso coherente. Al final nos reímos mucho, en fin, a veces tenemos que recordarle al norte que el sur también existe (Risas) (profesora C.).

El liceo trata de hacerse cargo, a su manera, de esos cruces entre distintas tradiciones, temporalidades y espacios. En cierto sentido, la Feria Intercultural es el momento del año para expresar y mostrar la supuesta diversidad presente en este espacio escolar, incluso aquellas que pueden ser contradictorias o paradójicas, que tiene resonancias de esas culturas híbridas que señalaba García Canclini (2003). De ese modo, el título de "Feria" expresa, valga la redundancia, una suerte de "feria de las variedades" donde lo diverso excede a lo étnico y a lo migrante. 
No es baladí, que en el lenguaje coloquial se hable de "stand" para referirse a los puestos específicos de cada Cultura o Nacionalidad. Y no lo es, porque estamos en presencia del reflejo más nítido de la "estandarización" de la cultura. Pese a los anhelos de una interculturalidad más crítica (Tubino, 2005; Walsh, 2008) y menos folclorizante como anhelan, y expresan en conversaciones informales, las coordinadoras del área intercultural del Liceo, se sigue manifestando (y perpetuando) la imagen de la cultura como un "gabinete de curiosidades" como lo señala irónicamente Gunther Dietz (2003).

Además, esa noción de lo estandarizado también alude a la marcada y recurrente similitud de los elementos y símbolos expuestos en las distintas tiendas. Referido a comidas, emblemas patrios, colores, artesanías o vestimentas típicas.

\section{CONCLUSIONES}

Se está en presencia de una exhibición de repertorios culturales, supuestos elementos característicos de esas culturas, poniendo en la vitrina símbolos patrimoniales dotados en apariencia de un sentido identitario. Pero se hace evidente la ausencia de un contexto que los explique, de un relato que les de coherencia y unidad, o al menos que plantee una discusión sobre su complejidad. Algo notorio en este aspecto es que, en la Feria Intercultural conmemorativa del 12 de octubre, no hay stand de Chile ni de España, probablemente porque se asocian con las culturas dominantes y por tanto, continuando con esa lógica, no requerirían "visibilización", ni "sensibilización".

En ese sentido, es notorio que la mayor diferencia entre los stands descritos es que el de Palestina asume un tono político de evidente denuncia, representando los conflictos y pesares que comparte su comunidad. Mientras que en el caso de las tiendas de los países de América Latina están invisibilizados los conflictos. Por el contrario, aparece el poder evocador del Estado Nación en todo su carácter dominante, a través de símbolos característicos de la patria. Pero no se alude a tensiones históricas y ni siquiera se menciona lo que significó la conquista española del continente, precisamente el hito clave que conmemora esta feria.

Al emplear dispositivos de este tipo, como la Feria Intercultural, el liceo busca generar un vínculo social que permita desarrollar esa impronta de valorización de lo migrante en su comunidad escolar, compartir tentativamente ciertos valores de convivencia que garanticen relaciones de respeto con esa otredad diferenciada y categorizada como tal. Pero lo lleva a cabo a través de una puesta en escena marcadamente gestual, pues en la diversidad de tiendas y de elementos expuestos que trata de plasmar la institución escolar, puede apreciarse una imagen truncada y oblicua sobre la diversidad cultural presente en la escuela, que viene a representar una suerte de caleidoscopio intercultural.

\section{REFERENCIAS BIBLIOGRÁFICAS}

Anderson, B. (2007). Comunidades imaginadas. Reflexiones sobre el origen y la difusión del nacionalismo. México D. F.: Fondo de Cultura Económica.

Boas, F. (2008). Franz Boas: Textos de antropología. Madrid: Editorial universitaria Ramón Areces. Benedict, R. (1971 [1934]). El hombre y la cultura. Buenos Aires: Centro Editor de América Latina. 
Bolados, P. (2006). La educación intercultural atacameña en los procesos étnicos actuales: Aproximación, análisis y comprensión de los discursos en los principales agentes que la implementan (tesis magister). Instituto de Investigaciones Arqueológicas y Museo. Universidad Católica del Norte, San Pedro de Atacama.

Bourdieu, P. \& Passeron, J. (1996). La reproducción. México D.F.: Distribuciones Fontamara.

Bustos, R. \& Gairín, J. (2017). Adaptación académica de estudiantes migrantes en contexto de frontera. Calidad en la educación, (46), 193-220. http://dx.doi.org/10.31619/caledu.n46.7

Canales, M., Bellei, C. \& Orellana, V. (2016) ¿Por qué elegir una escuela privada subvencionada? Sectores medios emergentes y elección de escuela en un sistema de mercado. Estudios pedagógicos (Valdivia), 42(3), 89-109. https://doi.org/10.4067/s0718-07052016000400005

Catalán, R. (2013). Prácticas y discursos pedagógicos en Toconao. Cultura, patrimonio e interculturalidad. Estudios Atacameños, (45), 19-40. https://doi.org/10.4067/s071810432013000100003

Chiodi, F. \& Bahamondes, M. (2001). Una escuela, diferentes culturas. Temuco: Corporación Nacional de Desarrollo Indígena.

Crenshaw, K. (2002). Documento para o encontro de especialistas em aspectos da discriminação racial relativos ao gênero. Revista Estudos Feministas, 10(1), 171-188. https://doi.org/10.1590/ s0104-026x2002000100011

Díaz de Rada, Á. (1996). Los primeros de la clase y los últimos románticos: Una etnografía para la crítica de la visión instrumental de la enseñanza. Madrid: Siglo XXI.

Dietz, G. (2003). Hacia una Antropología de la interculturalidad. Granada: Editorial Universidad de Granada.

Flick, U. (2007) Introducción a la Investigación Cualitativa. Madrid: Morata.

Franzé, A. (2005). Discurso experto, educación intercultural y patrimonialización de la cultura de origen. En G. Carrera \& G. Dietz (Eds.). Patrimonio inmaterial y gestión de la diversidad (pp. 297-315). Granada: IAPH/ Junta de Andalucía.

Garcés, A. (2011) De enclave a centralidad. Espacio urbano, comercio y migración peruana en Santiago de Chile. Gazeta de Antropología, 27(2), 1-24. http://hdl.handle.net/10481/18981

García Canclini, N. (2003) Culturas híbridas. Buenos Aires: Paidós.

Geertz, C. (1989). La interpretación de las culturas. México: Gedisa.

Guber, R. (2005). Etnografía: Método, campo y reflexividad. Buenos Aires: Norma.

INE-DEM. (2020). Estimación de personas extranjeras residentes habituales en Chile al 31 de diciembre 2019: Informe técnico. Santiago: Instituto Nacional de Estadísticas y Departamento de extranjería y migración.

Jiménez, F. \& Fardella, C. (2015). Diversidad y rol de la escuela. Discursos del profesorado en contextos educativos multiculturales en clave migratoria. Revista Mexicana de Investigación Educativa, 20(65), 419-441. Última visita 20 junio de 2018. Recuperado desde http://www. scielo.org.mx/scielo.php?script=sci_arttext\&pid=S1405-66662015000200005\&lng=es\&tlng=es

Jiménez, F. (2014). Modelos de gestión de la diversidad cultural para la escolarización de alumnado inmigrante en las escuelas chilenas: desafíos para la interculturalidad actual. Estudios Pedagógicos (Valdivia), 40(2), 409-426. https://doi.org/10.4067/s0718-07052014000300024

Lahire, B. (2004). El hombre plural. Los resortes de la acción. Barcelona: Bellatera.

Mead, M. (1985 [1930]). Educación y cultura en Nueva Guinea. Barcelona: Paidós.

MINEDUC (2020). Apuntes: Variación de la matrícula preliminar 2020. Santiago: Unidad de Estadísticas, Centro de Estudios.

Pavez, I. (2012). Inmigración en Chile. Experiencias de la niñez peruana en Santiago de Chile. Revista de Estudios Transfronterizos, 12(1), 75-99.

Riedemann, A. \& Stefoni, C. (2015). Sobre el racismo, su negación, y las consecuencias para una educación antirracista en la enseñanza secundaria chilena. Polis, 14(42), 191-216. https://doi. org/10.4067/s0718-65682015000300010 
Rivera Cusicanqui, S. (2010). Violencias (re) encubiertas en Bolivia. La Paz: Editorial Piedra Rota.

Stefoni, C., Acosta, E., Gaymer, M. \& Casas-Cordero, F. (2008). Niños y niñas inmigrantes en Santiago de Chile. Entre la integración y la exclusión. Santiago: OIM- UAH.

Stefoni, C. (2003). Inmigración peruana en Chile. Una oportunidad a la integración. Santiago: Editorial Universitaria.

Tijoux, M. E. (2016). Racismo en Chile. La piel como marca de la inmigración. Santiago: Editorial Universitaria.

. (2013). Las escuelas de la inmigración en Santiago de Chile: Elementos para una educación contra el racismo. Polis 12(35), 287-307. https://doi.org/10.4067/s0718-65682013000200013

(2007). Peruanas migrantes en Santiago. Un arte cotidiano de la lucha por la vida. Polis 18. s/p. Última visita 22 junio de 2018. Recuperado desde http://journals.openedition.org/ polis $/ 4185$

Tubino, F. (2005). La interculturalidad crítica como proyecto ético-político. Lima: Encuentro continental de educadores agustinos. Última visita 26 abril de 2012. Recuperado desde http:// oala.villanova.edu/congresos/educación/lima-ponen-02.html

Viveros, M. (2016). La interseccionalidad: Una aproximación situada a la dominación. Debate Feminista, (52), 1-17. https://doi.org/10.1016/j.df.2016.09.005

Walsh, C. (2008). Interculturalidad crítica, pedagogía decolonial. En W. Villa \& A. Grueso (Eds.). Diversidad, interculturalidad y construcción de ciudad. Bogotá: Universidad Pedagógica Nacional/Alcaldía Mayor.

Willis, P. (2006). Producción cultural no es lo mismo que Reproducción cultural, que a su vez no es lo mismo que Reproducción social, que tampoco es lo mismo que Reproducción. En H. Velasco, F. García, \& A. Díaz de Rada (Eds.), Lecturas de antropología para educadores (pp. 431-461). Madrid: Trotta. 
